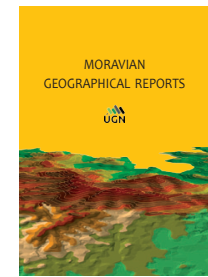

MORAVIAN GEOGRAPHICAL REPORTS

The Czech Academy of Sciences, Institute of Geonics

journal homepage: http://www.geonika.cz/mgr.html

doi: https://doi.org/10.2478/mgr-2020-0021

\title{
A diversity of patterns: 10-year trajectories of men and women diagnosed with psychosis for the first time. A time-geographic approach
}

\author{
Gunnel ANDERSSON ${ }^{\text {a }}$, Katerina VROTSOU b, Anne DENHOV c, Alain TOPOR ${ }^{\mathrm{c}, \mathrm{d}}$, \\ Per BÜLOW e,f ${ }^{\text {, Kajsa ELLEGÅRD }}{ }^{\mathrm{g}}$
}

\begin{abstract}
People with severe mental illness face a different 'interventional' landscape compared to some decades ago, when mental hospitals were dominant, in Sweden as well as in the rest of the Western world. The aim of the research reported in this article was to follow men and women diagnosed with psychosis for the first time over a 10-year period, and to explore what interventions they experienced. The interventions, here defined as "spheres", were either community-based or institutional. A third sphere represents no interventions. Based on data from registers and using a time-geographic approach, the individuals were visualised as 10year trajectories where their transitions between the different spheres were highlighted. The results show a great diversity of trajectories. Two main categories were detected: two-spheres (community-based and no interventions) and three-spheres (adding institutional interventions). One third of the population experienced only community-based interventions, with a higher proportion of men than women. Consequently, more women had institutional experience. Two sub-categories reveal trajectories not being in the interventional sphere in a stepwise manner before the 10th year, and long-term trajectories with interventions in the $10^{\text {th }}$ year. The most common pattern was long-term trajectories, embracing about half of the population, while one-fifth left the institutional sphere before the $5^{\text {th }}$ year.
\end{abstract}

Keywords: trajectories, psychosis, interventions/no interventions, time-geography, visualisation, gender, Sweden

Article history: Received 26 February, Accepted 25 October 2020, Published 31 December 2020

\section{Introduction}

When a person is faced with a diagnosis of severe mental illness (SMI), society will look upon, evaluate and treat the person, differently depending on when [in time] and where [geographically] this occurs. Until some decades ago, large-sized mental hospitals were the common form of treatment in the Western world, where people could spend years of their lives, secluded from the surrounding world. These hospitals have been called total institutions, referring not only to their size and foreclosure function, but equally to the individuals' collective submission to a totalitarian social system, regulating all aspects of their lives. The patients lived their lives in one limited institution, overlooked by an authority which replaced the different ways to live a "normal" life, outside the institutions: homes, workplaces, cinemas, stores, restaurants, forests, parks, etc. (Goffman, 1961). Hence, substantial control of the individual comprised all parts of everyday life with little or no regard to the individuality of the individual.

\footnotetext{
${ }^{a}$ FoU Södertörn, Research \& Development Center, Handen, Sweden (*corresponding author: G. Andersson, e-mail: gunnel.andersson@fou-sodertorn.se)

${ }^{\mathrm{b}}$ Department of Science and Technology, Linköping University, Norrköping, Sweden

${ }^{\mathrm{c}}$ Department of Social Work, Stockholm University, Stockholm, Sweden

${ }^{\mathrm{d}}$ Department of Psychosocial Work, University of Agder, Norway

${ }^{\mathrm{e}}$ Department of Social Work, School of Health and Welfare, Jönköping University, Jönköping, Sweden

${ }^{\mathrm{f}}$ Forensic Psychiatric Regional Clinic, Vadstena, Sweden

${ }^{g}$ Department of Thematic Studies (TEMA), Technology and Social Change (TEMAT), Linköping University, Linköping, Sweden
} 
For several decades now, de-institutionalisation has been the core-word for the development of new forms of interventions, basically meaning the closure of mental hospitals and the development of community-based interventions (Topor et al., 2015; Oots et al., 2013). This process aimed inter alia to normalise and improve the living conditions for persons with SMI (Marklund, 2005), to ensure citizen rights and enhance autonomy (Davidson et al., 2010). Even if this development can be problematised (for example, concerning economic improvement: see Topor et al., 2019), there has been a major change of living conditions for persons with SMI, in Sweden as in many parts in the Western world (Becker and VázquezBarquero, 2001; Priebe et al., 2005; Priebe et al., 2008). In Sweden, this change mainly took place during the 1980s and 1990s (Lindqvist et al., 2010; Topor, et al., 2015) and out-patient facilities, organised by the regional psychiatric care, and various types of social support, organised by the municipalities, were developed (Topor et al., 2015). Still, institutional interventions in terms of 24-hour care exist in terms of psychiatric inpatient care and supported housing, the latter organised by the social service sector.

The development towards community-based support has led to the involvement of different organisations providing interventions (Topor et al., 2011). As a result, persons with SMI are now facing an interventional landscape considerably different from the era of the mental hospitals. Although this development has been ongoing for several decades, little is known concerning what interventions persons with SMI are actually subject to. Interestingly, there is little knowledge about whether there are periods of no interventions over time as well. This gap of knowledge is somewhat striking, since the ultimate aim of interventions is to help the persons obtain a self-managed life.

As stated earlier, the interventions directed towards persons with SMI, were enacted at an institution of "brick and mortar" at one place, which also enclosed just about every aspect of a person's life. Mental health geographers have stressed the importance of connecting SMI and societal changes and integration to place (De Verteuil et al., 2007) and activity space (Townley et al., 2009). This development has further been described in terms of a "post-asylum landscape" (Larsen and Topor, 2017), a "new institutional landscape" (Topor et al., 2015) or "landscapes of de-institutionalisation" (Wolch and Philo, 2000), all referring to physical terrain. In the wake of this development, the concept of a "fragmented interventional landscape" is used in this article (Andersson et al., 2019). The fragmentation refers to the appearance over time of the different organisations now operating in the field, representing different types of interventions enacted in different places and "spheres".

The concept of "spheres" used in this study corresponds to what kinds of interventions persons diagnosed with psychosis are subject to. They might be embedded in an institutional sphere, including inpatient care or supported housing; or their lives might take place in a community-based sphere, where they live in a regular setting with community-based support of different kinds from different actors. A third sphere, vital in this study, is the non-interventional sphere which corresponds to shorter or longer periods with no interventions in a person's life. ${ }^{1}$
The transitions of each unique person between these three spheres can be seen as their trajectories over the 10 -year period under study. By using different colours to represent each sphere, these trajectories are visualised, making it possible to follow the timing (when and for how long) and sequence in which persons with SMI move between spheres.

The use of the concept "trajectory" or "course", is quite common in follow-up studies of persons with SMI, although the 'object' of what is being followed and "trajectorised" in such studies is rather diverse, as well as the duration of the follow-up periods. In general, follow-up studies of persons with SMI are afflicted with short follow-up periods (PelayoTerán et al., 2014), as well as missing data (Hegelstad et al., 2012; SBU, 2012) - and not including the diversity of interventions appearing (Topor et al., 2015). Another problem is that follow-up studies just pin-point specific moments and thereby miss continuity over time (see for example, Harrison et al., 2001; Wiersma et al., 1998). The focus in follow-up studies using the term trajectory or course, vary: such studies have a clinical focus, such as cognitive or social functioning (Barder et al., 2014, 2015; Gonzales-Blanche et al., 2015; Hall et al., 2015; Milev et al., 2005; SanchezTorrez et al., 2017), while others focus on symptoms (Abdin et al., 2017; DeVylder et al., 2014; Pelayo-Terán et al., 2014) and treatment response (Levin et al., 2010). There are also studies with a more global outcome perspective, including living conditions (Ciompi, 1980; Green et al., 2013; Harrison et al., 2001; Wiersma et al., 1998). Long-term follows-up exposing continuous trajectories on an aggregated level, revealing both patterns of and no interventions and including the diversity of interventions from different organisations do not, to our knowledge, exist.

One important result from studies with long follow-up periods is stated by Ciompi (1980, p. 420):

"...there is no such thing as a specific course of schizophrenia. (...) In the light of long-term investigations, what is called 'the course of schizophrenia' more closely resembles a life process open to a great variety of influences of all kinds than an illness with a given score."

Twenty years later Harrison et al. (2001, p. 516) concludes in a 15-year follow-up that:

\footnotetext{
"Striking heterogeneity in the long-term course of schizophrenia challenges conventional notions of chronicity and therapeutic pessimism."
}

The course of psychosis has also been investigated through biographical trajectories, relating to how the experience of psychosis constituted the notion of the self, culminating in five different types of trajectories with a variety from being 'subsumed by' to 'assume agency' over the experiences, the latter relating to examples of recovery (Georgaca and Zissi, 2019).

Lastly, few follow-up studies have been conducted in Sweden (SBU, 2012), and the ones that are have mostly a clinical focus, with some exceptions (Arvidsson, 2008; Bülow, 2004; Kjellman, 2003).

Hence, there is a need for studies including the different types of interventions provided in the fragmented interventional landscape that has developed after de-

\footnotetext{
${ }^{1}$ The definition of the different spheres occurring in the trajectories originates from a study in which everyday life was analysed on a daily level related to time and space (see Andersson, 2009). In this study the unit of analysis is ten years, but the spheres are still applicable.
} 
institutionalisation. It is important to minimise drop outs (which is possible by the Swedish personal registration number) and to follow the indivisible continuous courses of indivisible individuals in a longtime perspective. Since the significance of a gender perspective in mental health studies has been stressed (Schön, 2010), we have acknowledged that as well.

In a previous article we focused on the trajectories of interventions (Andersson et al., 2019), investigating which type of intervention occurred in a trajectory, when and for how long. We found, for example, that while it was more common among women to be subject to institutional interventions, men spent more time in the institutional sphere since the sequences of institutional care in the trajectories of men were longer. Further, we found that community-based interventions played an important role for both men and women, related to the recurring appearances in the trajectories. While the frequency of community-based interventions showed a slight decline after a few years among women, it increased among men. Another important and interesting result from the former study is that up to $70 \%$ of the total accumulated time over the 10 years for the total population, is time without interventions (ibid.). This will be further explored in this article.

The aim of this article is to explore the course of interventions and no interventions in the continuous trajectories over 10 years of men and women, after being diagnosed with psychosis for the first time. Thereby we could identify in what spheres persons with severe mental issues live their lives over the period. The research questions, related to gender, focus on: What patterns can be identified and how can they be categorised? Since the previous study (Andersson et al., 2019) focused on patterns of interventions, this study takes a major point of departure in the sphere of no interventions.

This is the third article using a time-geographic visualisation method, created especially for the Stockholm 10-year follow-up study of persons diagnosed with psychosis for the first time (see Andersson et al., 2019; Vrotsou et al., 2017). This new interactive method visualises individual trajectories of interventions, based on individual data, at an aggregate level. The visualisation method is inspired by time-geography (Ellegård, 2019; Hägerstrand, 1970). The previous published studies using this method of visualisation had different foci compared to the present study with its orientation towards patterns. The aim in Vrotsou, et al. (2017) was to thoroughly present and explain the method (data conventions, functionality, visual representation) and how it could be used on the dataset

\begin{tabular}{cccr}
\hline Ages & Men & Women & All \\
\hline $18-24$ & $26(13 \%)$ & $18(10 \%)$ & 44 \\
$25-34$ & $54(26 \%)$ & $45(27 \%)$ & 99 \\
$35-44$ & $72(35 \%)$ & $43(24 \%)$ & 115 \\
$45-54$ & $36(17 \%)$ & $31(18 \%)$ & 67 \\
$55-64$ & $11(5 \%)$ & $25(14 \%)$ & 36 \\
$65-74$ & $8(4 \%)$ & $4(2 \%)$ & 12 \\
$75-84$ & 1 & $9(5 \%)$ & 10 \\
$85+$ & 0 & 1 & 1 \\
$\mathbf{Z}$ & $208(100 \%)$ & $176(100 \%)$ & 384 \\
\hline
\end{tabular}

Tab. 1: Age distribution at the time of diagnosis, 384 men and women. Source: authors' research by showing some preliminary results. In Andersson et al. (2019), the appearances and frequencies of different types of interventions were exposed. The visualisation concentrated on one intervention at a time, not revealing patterns of fully exposed trajectories. The periods of no interventions were not explored as well. In the present article we take a step further and follow the courses, including the spheres of no intervention. This specific study is a part of a larger research project: "Persons with severe mental illness - living conditions, interventions and paths. A ten-year follow-up." The research team has an interdisciplinary background in social work, psychology, nursing, human geography and visualisation science.

\section{Data}

\subsection{The study population}

The study population consists of all persons who were diagnosed with psychosis for the first time between the years of 2000 and 2004, in all 447 individuals, in the catchment area of a mental health organisation in the southern part of Stockholm (with a total count of 282,000 inhabitants, of which 232,000 were 18 years of age and older). The catchment area includes inner-city parts as well as older and new suburban areas, with a diverse socio-economic population. The criteria for inclusion in the study were a psychosis diagnosis that complied with DSM-III-IV (Diagnostic and Statistical Manual of Mental Disorders) or ICD 10 (International Statistical Classification of Diseases and Related Health Problems). The included individuals should also have been in contact with the psychiatric care organisation during the year 2004. The study, then, is a longitudinal and naturalistic cohort study. All patients with psychosis diagnoses, according to the inclusion criteria, were included and the data presented reflected a psychiatric organisation that offered psychiatric care according to treatment as usual (TaU).

The follow-up period was ten years for every individual from the date of the diagnosis. This means that year " 0 " can differ, from year 2000 to year 2004. Out of a total population of 447 , ten were missing in the registers, resulting in a total population of 437 persons. The 53 persons who died during the period ( 22 women and 31 men) are not included in this study, leaving a total of 384 individuals. There is a higher share of elderly women compared to men: $21 \%$ of the women and $9 \%$ of the men were over 55 years of age at the time of the diagnosis, turning 65 and more during the study period. This could have had an impact on what types of interventions the person is subject to (see Limitations).

\subsection{Data and databases}

Data for this study were collected from several registers. In Sweden, each citizen has a personal 'registration number' which facilitates the possibility to conduct follow-up studies with a minimum of dropouts. These numbers, connected to the persons in the study, appear in all registers used. After the approval of a Board of Ethics, data from different registers can then be linked together. This study was approved by The Regional Ethical Review Board (EPN) in Stockholm in 2005 (2005/ 2:1), in 2009 (2009/806-32) and in 2015 (2015/115532).

Data collected from which registers are presented in Table 2. For a more detailed description, see Topor et al. (2011).

By combining the different registers it is possible to reveal what spheres the individuals go between and, thereby, what different types of interventions they meet, how often these 


\begin{tabular}{ll}
\hline Databases & Data collected \\
\hline National Board of Health and Welfare-Hospital Register & Psychiatric inpatient care and diagnosis \\
Stockholm County Council - Psychiatric activity database (PVS) & Psychiatric out-patient care \\
Swedish National Council for Crime Prevention & Type of sanction* \\
Stockholm Municipality - Social Services database & Financial assistance, social support in daily living, occupational \\
& and rehabilitation interventions \\
Cause of Death Register & Death and cause of death \\
\hline
\end{tabular}

Tab. 2: Databases used and data collected. Source: authors' research

Note: * Nobody in the study-population was sent to jail during the follow-up period but seven men (five under 30 years old) were sentenced to forensic psychiatry)

interventions occur, for how long they last and from what organisation they originate. It is also possible to detect when the persons are subject to interventions and when they are not, at individual as well as group levels.

The data refer either to interventions from the regional psychiatry care or the municipalities' social services. Psychiatric care is divided between community-based interventions like medication and therapeutic support, and inpatient interventions. Social services embrace communitybased social support specialised for persons with SMI-like support in daily living, occupational/activity support and supported housing with access to staff.

The intervention events collected from the registries are of varying temporal granularity, ranging from minutes (telephone call) to months or years (institutionalisation). In the data used in the study, the smallest time unit describing events has been set to a day. This implies that interventions with a duration less than a day (such as "phone calls or visits) are considered instantaneous events and characterised by a daily time stamp, while longer interventions are considered as event intervals and characterised by a starting and end day.

\section{Method and theoretical approach}

The theoretical and methodological framework of this study is based on time-geography. As the concept of timegeography indicates, both time and space are important dimensions in a time-geographic approach, with the possibility to utilise different geographical and time scales (Ellegård, 1983; Hägerstrand, 1970, 1972, 1973, 1974; Lenntorp,1976). A fundamental aspect of time-geography is the indivisible individual, reflecting the fact that the individual lives continuously during her lifetime, hence, the individual is indivisible. Indivisibility indicates that it is not possible for an individual to exist at several places at the same time. Consequently, all actions taking place in a person's life are sequentially tied to that individual in time and space. Furthermore, time-geography provides a notation system enabling the representation of an individual's continuous movement in time and space, which can be geographic or abstract space. In this study, the trajectories of individual men and women are visualised across the abstract space made up from the spheres of interventions, and taken together, they constitute an aggregated view of the population under study. In this way, continuous sequences of interventions, not seldom interrupted by periods of no interventions, are visualised, in analogy with the idea of the indivisible individual. Time-geography provides both concepts and methods for visualising individuals over time by continuous trajectories, which are suitable for longitudinal studies.
The spheres, which correspond to the individual's relations to different kinds of institutions providing interventions at different places, emanate from a qualitative everyday life study of persons with SMI (Andersson, 2009). Using time geographic diaries, Andersson constructed trajectories of the individuals' everyday life, hour by hour. A trajectory formed from time geographic diaries can clarify the individual's geographical, temporal and social anchoring. Consequently, by following the trajectory of an individual, different contexts of everyday life are revealed (Ellegård, 2001, 2019). The contexts identified by Andersson (ibid.) related to psychiatric and social interventions, including people and places of significance in everyday life. She also identified periods in life without interventions, and its social, temporal and geographical connotations. These contexts formed different conditions and framed everyday life (Andersson, 2009). The contexts discovered - community-based interventions, institutional interventions and no interventions - were then transformed into "spheres", a concept which can comprise abstract places with their various societal organisations and connotations, as well as physical places. The spheres, then, demonstrate a way to relate individual experiences and societal structures for persons with severe psychiatric problems, and they represent abstract places defined by their functions and rules. The community-based sphere includes places like outpatient clinics and activity centres, but also a person's home can be a place for intervention. Besides interventions and a social world populated by professionals, this sphere is represented by ordinary living and a varying extent of informal relations. The institutional sphere includes places like psychiatric clinics and supported housing, and the daily social contacts can be limited to staff and other patients/ co-habitants (but potentially also friends and family). The no interventional sphere includes the home and most of the routine places where people perform activities in daily life, and the social contacts can be varied. This sphere can be interpreted as "normalised" living, in which the individual manages with no interventions.

Individuals have limited possibilities of action, and to deal with this in time-geography, three basic constraints are identified (Lenntorp, 1976; Hägerstrand, 1985; Åquist, 1992): authority, coupling and capacity constraints. Capacity constraints embrace the individual's physical and mental capacity, material assets, knowledge, etc. and are expressed in the interactions between the individual and the social, material and physical environment. One capacity restriction of people in this study is their psychiatric problems. Authority constraints refer to laws, rules, policies, etc. They exist at an organisational level and orchestrate the individual's room for manoeuvre; hence, it is problematic for the individual to change or influence 
them. In this study, extensive authority constraints can be imposed on persons in special institutional settings in the institutional sphere, and less, but still substantial authority constraints influence the individual when in the community-based sphere, where the private home can be the base for daily life. Coupling constraints relate to individuals' opportunities to interact, i.e. to be in the same place at the same time as another individual and are based on agreements, negotiations and obligations. Coupling constraints are specifically time-geographic constructs and they reveal that there are several restrictions in a person's life caused by location, timing of activities and projects and decisions taken by others. They shed light on interdependencies and the importance of everyday logistics. The different types of constraints are mutually interrelated, and they affect peoples' opportunities to interact and to live their lives (Ellegård, 1998; Westermark, 2003). As indicated, the different spheres reflect different types of constraints, which will be further developed in the following discussion.

In this study, (as well as in Andersson et al., 2019, and Vrotsou et al., 2017) the geographical dimension is 'toned down', although it is reflected in the different spheres corresponding to locations in a "fragmented interventional landscape". A person in the non-interventional sphere lives (most likely) ${ }^{2}$ in a regular setting in society. The communitybased sphere indicates a regular living situation combined with social support or medication, while the institutional sphere indicates that a person either is in a clinical setting $24 / 7$ or in supported housing with staff.

\subsection{The principle of visualisation}

Figure 1 shows the principle of the visualisation used in this study. It is based on the trajectories of five persons, from the first year of the diagnosis of psychosis to the $10^{\text {th }}$ year. Each person's path of intervention is represented as a bar-formed trajectory corresponding to their sequence of interventions over the 10 years under study. Time is represented on the vertical y-axis, while the horizontal $\mathrm{x}$-axis displays the individuals, ordered side by side. The position of each bar along the y-axis corresponds to the start time of the corresponding event and its length depends on the duration of the event. If the event is instantaneous a bar of fixed size is used. The width of the bars is proportional to the size of the screen and the number of individuals displayed simultaneously. Hence, the trajectory of an individual should be read from the bottom to the top of the figure. The colours correspond to the different spheres: community-based interventions are marked in blue, institutional interventions in red, and time-periods without interventions are in white. When a person deceases, their remaining trajectory is coloured black (not shown in Fig. 1).

Trajectory A, to the left in the figure, visualises a person who initially mostly experiences institutional interventions (red) for almost three years. Then, for a short period, community- based interventions (blue) are mixed with periods of no interventions (white). For the rest of the 10-year period, this pattern persists: community-based intervention superseded by periods of no interventions with recurring short periods of institutional care. Trajectory B visualises a person who is subject to community-based interventions (blue) on and off for about a year and thereafter there are no interventions appearing for rest of the 10 years. Consequently, the white area after the last intervention is part of the continuous trajectory, when the person is in the non-interventional sphere for the rest of the 10-year period. Trajectory $\mathrm{C}$ visualises a person with the same initial pattern as B but with the last intervention around year six, meaning the trajectory continues into the interventional sphere a few years later than $B$. Thereafter, $C$ appears in the non-interventional sphere, with no further interventions. Trajectory D has a similar pattern as A, staying in the interventional sphere off and on for the whole period, but without any institutional interventions. The last example, E, reveals a trajectory with quite intense interventions, both community-based and institutional, for a year, then no interventions at all for five years and then community-based interventions at three more times for the rest of the period, leaving considerable periods of no interventions in between interventions. The trajectories of persons A and D exemplify what we call "long-term trajectories" and those of persons B, $\mathrm{C}$ and E exemplify "stepwise trajectories".

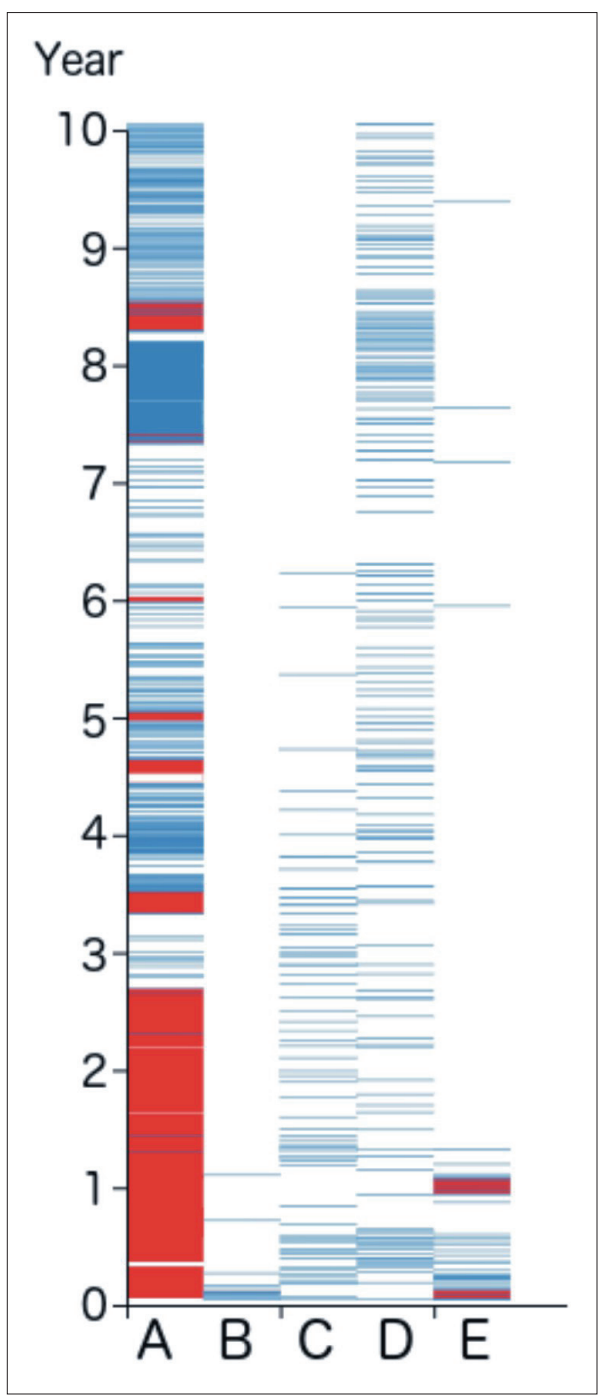

Fig. 1: Trajectories of five persons (A-E) with different experiences of the interventional spheres from $1^{\text {st }}$ year of diagnosis to $10^{\text {th }}$ year. The persons are arranged side by side on the $x$-axis, while the 10-year period constitutes the y-axis. Source: authors' elaboration

\footnotetext{
${ }^{2}$ Almost all the people in this study lived in ordinary housing at the time of the diagnoses. Data is missing concerning six persons. It is possible that some or all of them could be homeless.
} 
The principle of the aggregated pattern of trajectories was shown in Figure 1. In the same manner, the aggregate trajectory patterns of the total population are captured in Figure 2.

Taken together, all the trajectories reveal the aggregate pattern over the ten-year period. All trajectories are exposed side by side, men to the left, women to the right, divided by the yellow line. Year " 0 " is at the bottom line. The figure shows a diversity of trajectories where the red parts of a trajectory corresponds to time sequences at institutions and blue, community-based support. The white parts of a trajectory represent time without any interventions, and black the persons that died during the follow-up. In the present article, all these trajectories (minus the black) have been analysed and categorised.

It is crucial in this study that each individual is regarded as indivisible since the interventions that each individual is subject to and the sequences of no interventions oscillate between the different spheres over time, thereby, shaping the trajectory's sequential pattern of different spheres for each individual.

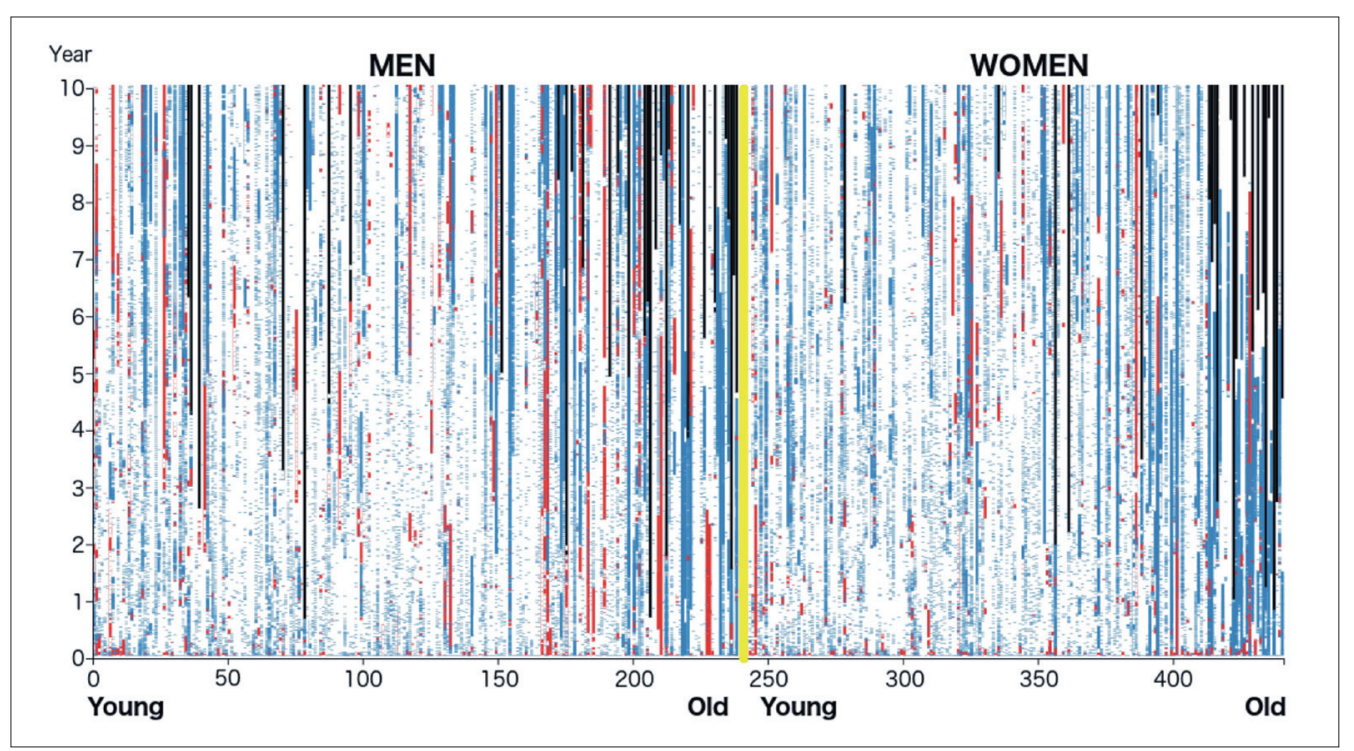

Fig. 2: All trajectories, including the dead (the trajectories are black after death), men to the left, women to the right Source: authors' elaboration

The system used for visualising and analysing data from the registers is web-based. The system was specifically designed for this follow-up study (and for the study presented in Andersson et al., 2019) and is fully presented in Vrotsou et al. (2017). The inspiration for the visualisation originates from Ellegård and Vrotsou (2006) and Vrotsou (2010). The visualisation method follows the time-geography approach in having its point of departure in the indivisible individual (Ellegård, 2019; Hägerstrand, 1970).

\subsection{Analyses}

For this particular study, the trajectories were organised manually during the analysis. The first principle of the categorisation emanated from what spheres could be detected in the trajectories and according to what pattern. Investigating each and every trajectory we found that no one included just one sphere, instead there were either just community-based interventions along with periods of no interventions, or both community-based and institutional interventions along with periods of no interventions. Then all trajectories were defined after this principle, resulting in two main categories: two-sphere trajectories and threesphere trajectories.

The next step was to identify patterns within these two main categories. Since the main point of departure was the pattern of no interventions, the trajectories were sorted with respect to the time of occurrence of the last intervention present in their trajectory. This revealed a step-like pattern starting with the shortest trajectory: i.e. having the last intervention ending earliest of all (just a few months after the time of the diagnoses) and gradually increasing until the longest trajectory is reached: i.e. including interventions spanning until the end of the 10 -year period. In sum the step-wise order shows when the trajectories "leave" the interventional sphere (blue or red) and continue in the non-interventional sphere (visualised by turning white) at different times up to the $10^{\text {th }}$ year.

In the further analyses, two subcategories of interventions emerged: stepwise intervention trajectories, displaying individuals not being in the interventional spheres up to the $10^{\text {th }}$ year, and long-term interventional trajectories, individuals still being in the interventional sphere the $10^{\text {th }}$ and last year. In that way we could analyse the patterns of trajectories not being in spheres of interventions and those still with interventions during the last and $10^{\text {th }}$ year, separately.

An important time unit in the analysis of the material is the full year. The choice of a year was two-fold. Being without interventions for a year shows a potential to manage without support for a substantial period of time. It also seemed to be the most effective way to visualise the discrepancy in patterns. A third sub-subcategory emerged from the longterm interventional trajectories: those with less than a year of coherent periods without interventions, revealing dense patterns of interventions and trajectories with a year or more with coherent non-interventional periods, which are defined as sparse patterns. This gave us a tool to further examine the long-term trajectories and, thereby, spot trajectories with the most long-lasting and intense patterns of intervention and the ones with less such features.

This article focuses on patterns of no-interventions in the trajectories. For a more thorough presentation of the interventional parts of the trajectories, see Andersson et al. (2019). 


\subsection{Limitations}

This study is affected by limitations, mainly concerning registration and categorisation. But the age distribution should be mentioned as well. Among women, 39 are over 55 years of age at the time of the diagnosis, and 20 men. In a ten-year perspective they turn 65 and older, reaching retirement age during the follow-up period. This could have implications on the types of interventions since social services has special interventions after 65 years, such as homes for elderly persons. Our data, however, show that only four persons (three women, one man) were subject to this type of institutional care (and mostly for short periods), meaning that most of the institutional interventions are connected to the psychiatric problems and not primarily to age.

Community-based psychiatry care and community-based social services register interventions differently. Psychiatric care registers every actual meeting with the person, while the social services register is based on formal decisions valid over a time period (for example, six months of social support). As a consequence, interventions from social services will sometimes appear as longer coherent (blue) parts in a trajectory. How often the actual intervention appears during this period is not known, but other studies reveal that, for example, social support in daily living often occurs once or twice a week (Andersson, 2009; Andersson et al., 2015). A similar coherent (blue) pattern will appear when psychiatric care has a frequent contact with a person, at least once a week. Less frequent contacts will appear as dots in the aggregate visualisations. This is a limitation in cases when interventions from social services appear more seldom than once a week, and then a similar dot-like pattern would be more relevant.

Another limiting factor is the potential effect of our visualisation choices in relation to the temporal aspect of the data. The total time span of the data is 10 years and within this time the minimum time unit with which interventions are represented is a single day. Over the entire 10-year study period interventions from different spheres can occur in parallel: for example, several community-based interventions can occur during longer institutional interventions. The large variation of interventions in temporal granularity, as well as their temporal overlaps, have a considerable effect on the visualisation of the data. Longer events or several short ones occurring consecutively appear more prominent in the representation, since they are visible as continuous long bars in the trajectories. At the same time, temporally scattered short events create a cluttered impression and become harder to distinguish. Moreover, overlapping interventions are also represented, overlapping in the visualisation which increases the clutter. Choosing a coarser temporal resolution, for example a monthly resolution, and applying temporal aggregation to the data would considerably reduce this clutter in the representation. This, however, would require us to choose a single intervention to be the representative ongoing event of that period, which would imply considerable loss of information. In our work we have chosen not to aggregate the data in this manner, partly because we wanted to retain the visibility of the large temporal variation, but more importantly because we did not want to lose information concerning the shorter (community-based) interventions by using a more coarse temporal resolution.

Categorisation demands choosing break points and those choices will impact the results (see for example, Topor et al., 2018). The choice of at least one year without interventions afflicts the creation of the two main categories and the distinction between dense and sparse patterns. A two-year limit, for example, would separate the trajectories differently but would not capture trajectories with tightly recurring interventions as well. Another way to categorise the trajectories could be to cluster the different spheres in order of appearance or amount of time spent in each sphere. The visualisation program in its current status, however, will not allow that, and to handle all spheres manually would be too complicated. This would be something to develop for future research.

It would have been an advantage to be able to make thorough and exact comparisons to the previous study focusing on the periods of interventions rather than periods without interventions (Andersson et al., 2019). This is due to the choice of not including the dead in this study, since there would be too many categories to overview. Although the 53 deceased persons are excluded here, the overall results from the two studies correspond and can therefore serve as references when needed.

Lastly, there might be persons diagnosed with psychosis between 2000 and 2003 that were not in contact with psychiatry in 2004, the year of inclusion. This means there might be more persons that we define as "early leavers" (not subject to any interventions after the $5^{\text {th }}$ year) in the catchment area, but not included in the study.

\section{Results}

The aim of this study was to explore the patterns of two kinds of interventions and no interventions in the trajectories of men and women after being diagnosed with psychosis for the first time, and to present the results according to sex. From the population of 384 persons, the results reveal trajectory patterns forming two main categories:

- Trajectories transitioning between two-spheres community-based interventions (blue) and no interventions (white); and

- Trajectories transitioning between three-spheres community interventions (blue), institutional interventions (red) and no intervention (white).

Within each category, two subcategories were defined depending on the distribution of interventions over the course of the 10-year study period, as was described above. First, trajectories including persons entering the noninterventional sphere in a step-wise order from the $1^{\text {st }}$ up to the $9^{\text {th }}$ year, which we define as "step-wise trajectories". Second, trajectories illustrating persons who are still involved in the interventional spheres during the $10^{\text {th }}$ and last year, which we define as "long-term trajectories". The results will be presented according to the scheme in Figure 3.

\subsection{Two-sphere trajectories}

The 112 men and women in the first main category composed of trajectories involving two spheres, have only experienced interventions from the community-based sphere combined with no interventions, for example social support in daily living, occupational/activity support, medication, therapeutic support, etc. Comparing the amount of men and women in this category, there are $62 \%$ men and $38 \%$ women.

Figure 4 displays all trajectories representing the two spheres in this category: community-based interventions (blue) and no interventions (white). Women are shown to 
the left and men to the right sorted in a step-wise pattern according to the time for their last occurring intervention (as described in Section 3.2: Analyses). In the following, in order to study the trajectories closer, the figure will be split up into two parts according to the subcategories defined: the stepwise trajectories (interventions within the first 9 years) and the long-term trajectories (interventions during the whole 10-year period).

\subsubsection{Stepwise trajectories}

Figure 5 illustrates trajectories transforming into the noninterventional sphere for the rest of the period in a stepwise order from the $1^{\text {st }}$ to the $9^{\text {th }}$ year (leaving at least a year at the end with no intervention). Out of the 43 women with only community-based interventions, 24 are found in this category. It is noticeable that more than half of these women (15) are not subject to any interventions after the $5^{\text {th }}$ year. We will refer to them as "early leavers", meaning that they leave the interventional sphere for the rest of the period.

Compared to women, there are relatively fewer "early leaving" men. Looking at the figure, there is a rising curve formed by the last interventions revealing around a third (12) without interventions after the $5^{\text {th }}$ year. Although the lowest common denominator in the stepwise category is that interventions cease to appear before the $10^{\text {th }}$ year, they show various patterns up to that time. Some of the trajectories among both men and women have substantial periods of no interventions between interventions. Others show a pattern of densely recurring interventions.

\subsubsection{Long-term interventional trajectories}

The subcategory long-term interventional trajectories includes trajectories of persons still appearing in the interventional sphere during the $10^{\text {th }}$ and last year. The patterns are quite diversified up to that point. Some have a pattern of dense recurring interventions during the whole period, and some have substantial periods of no interventions, just like the trajectories in the stepwise formation.

There are 19 women and 38 men with long-term trajectories. The trajectories with dense patterns are presented to the left in the sub-figures of Figure 6, and the ones with a more sparse pattern of interventions to the right, thereby spotting trajectories with the most long lasting and intense patterns of intervention and the ones with longer periods of no intervention. Among the women there are about as many trajectories with recurring dense

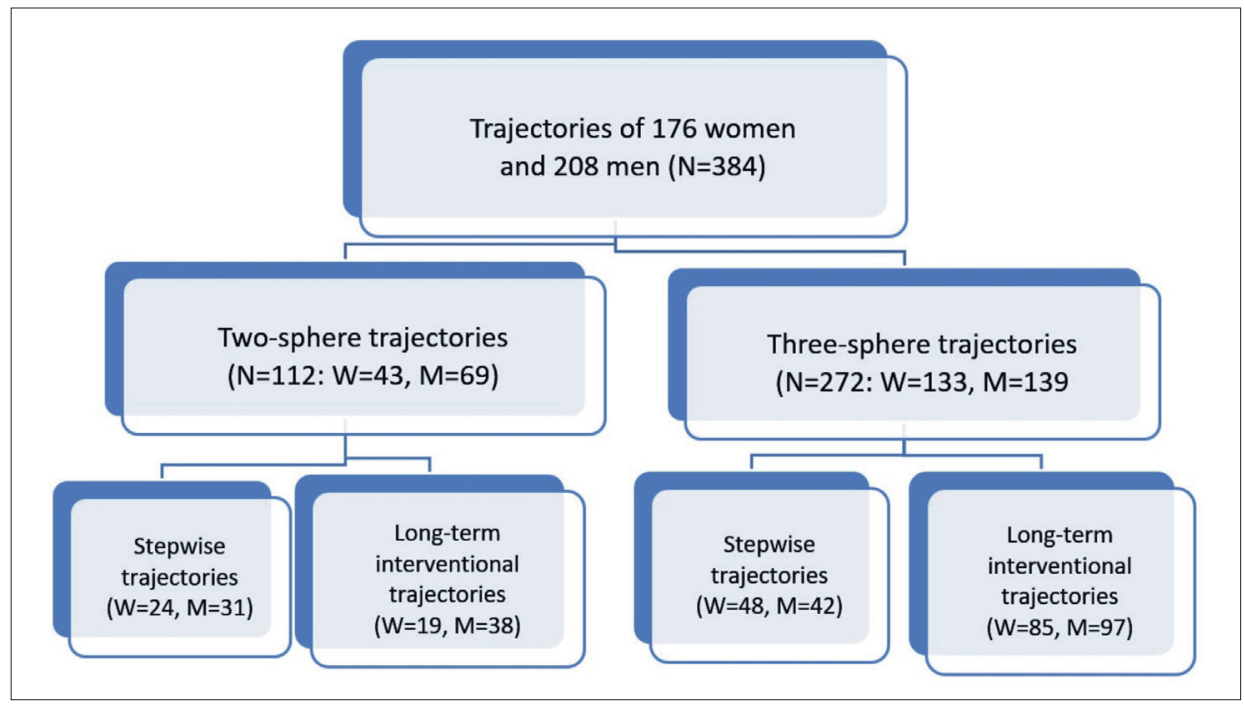

Fig. 3: Scheme of presentation of the results

Source: authors' elaboration

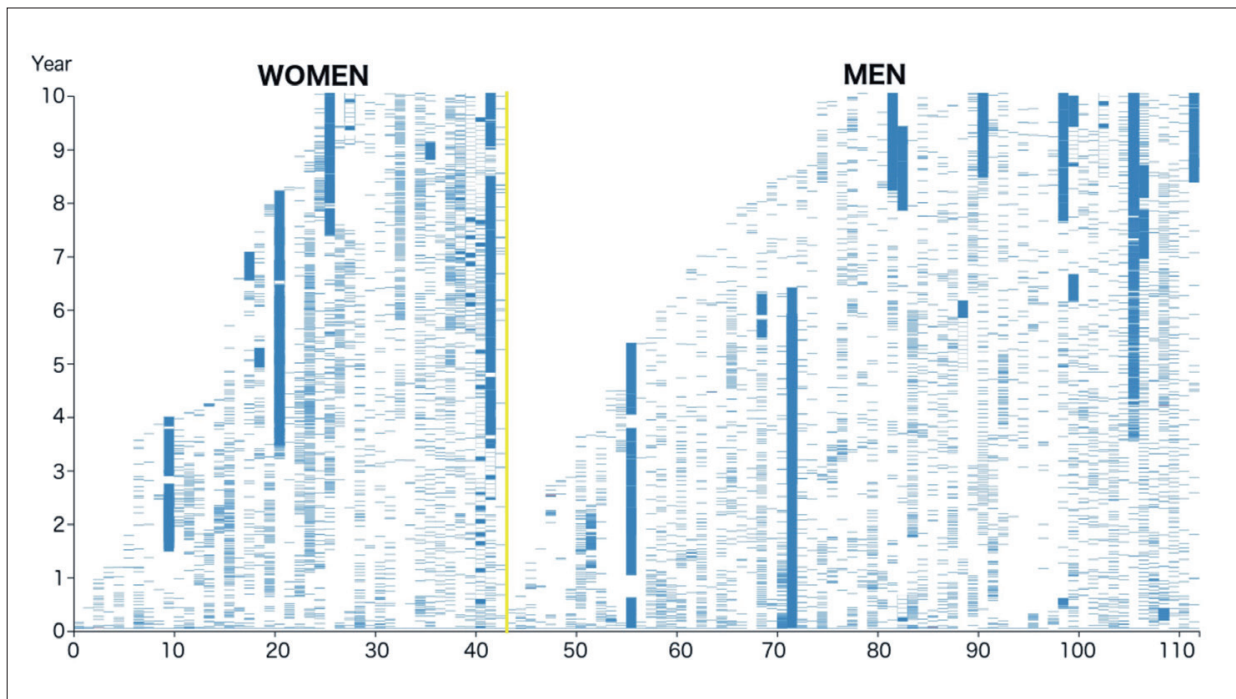

Fig. 4: Two-spheres trajectories: women to the left $(n=43)$, men to the right $(n=69)$

Source: authors' elaboration 
patterns of intervention as there are with extensive gaps without interventions. Among the men it is more common with a sparse pattern than dense. There are as long coherent periods without interventions of three to five years among women and three to eight years among men.

\subsection{Three-sphere trajectories}

The three-sphere main category reveals, not surprisingly, even more complex patterns, since institutional interventions (in-patient care or supported housing) are added to the community-based interventions and non-interventions. This category consists of 272 trajectories, about as many women, 133, as men 139 (Fig. 7).

This section will be organised in the same way as the two-sphere part, starting with trajectories in stepwise order followed by long-term trajectories.

\subsubsection{Stepwise trajectories}

Figure 8 exposes the stepwise trajectories of 48 women and 42 men, which is about a third of men and women respectively with institutional experience. More men (about half) than women (about a third) are "early leavers" in this category, noticed in a curve among men that is more levelled out. Compared to early leavers in the two-sphere category, the amount of men and women are reversed. In this category as well, the trajectories show various patterns up to the last intervention. Some show extensive periods of no interventions and some extensive periods of interventions. Comparing the different types of interventions (community-based and institutional), most of the institutional interventions occur as short periods in time, but, longer periods of institutional care also exist ${ }^{3}$.

\subsubsection{Long-term trajectories}

The next subcategory with three-spheres trajectories exposes long-term trajectories where the last intervention occurs during the $10^{\text {th }}$ and last year. As noted previously, there can be a substantial disparity in patterns.

There are 85 women and 97 men with long-term trajectories, including institutional experiences. The trajectories with dense recurring interventions are placed to the left and those with longer coherent periods of no intervention are presented to the right in Figure 9.

There are 50 women with dense patterns in their trajectories and 35 with sparse patterns. Most of the women with sparse patterns in their trajectories have around a year at a time without interventions, but some have coherent periods between two and as long as seven years. Among the men as well, dense patterns are more common than sparse (60 versus 37). Half of the trajectories with sparse patterns show periods of around a year and the rest between two and five coherent years without any interventions.

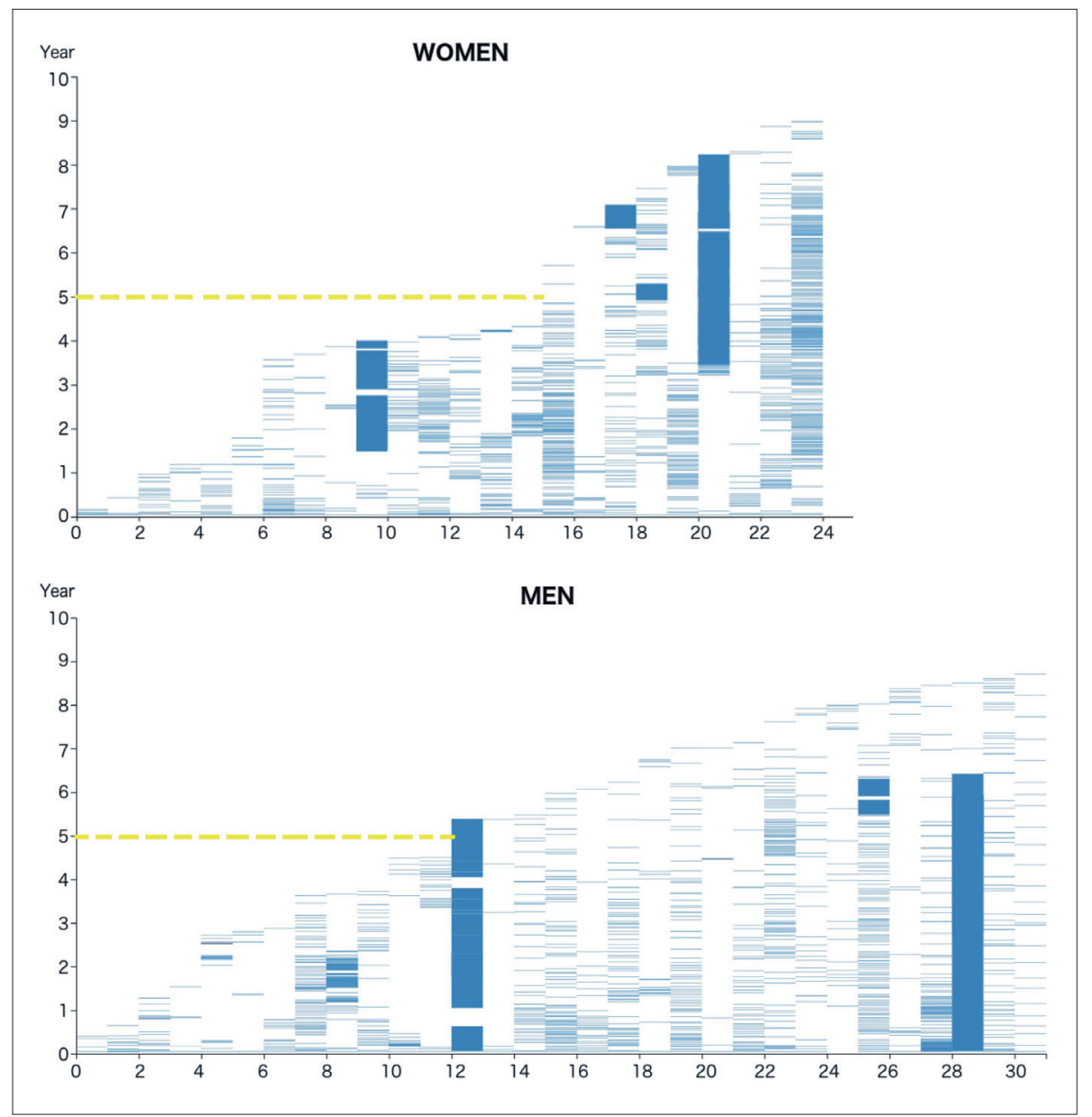

Fig. 5: Two-spheres stepwise trajectories: women at the top $(n=24)$, men below $(n=31)$ Source: authors' elaboration

\footnotetext{
${ }^{3}$ According to Andersson et al. (2019) the extensive periods of institutional interventions often correspond to housing rather than clinical care. The population in this article is not exactly the same as in Andersson et al. 2019, not including the dead, but the overall results from the two articles correspond
} 


\subsection{Summary}

In Table 3, the main results are compiled in percentage terms, according to sex. The distribution of stepwise and longterm patterns shows that long-term trajectories are more common for both women (60\%) and men $(65 \%)$. There is also a difference between the spheres in long-term trajectories: $11 \%$ of the women have only community-based interventions versus 48\% with institutional experience as well. Among men the discrepancy is $18 \%$ versus $47 \%$. Dense patterns in long-term trajectories with institutional interventions are more common than sparse, among both women and men. In the stepwise category we can notice that $18 \%$ of the women and $16 \%$ of the men can be referred to as "early leavers", not having any intervention for at least five years. While there is hardly any difference between the spheres among the women (8\% and 10\%), there are more men with institutional experience in this category ( $11 \%$ versus $6 \%)$.

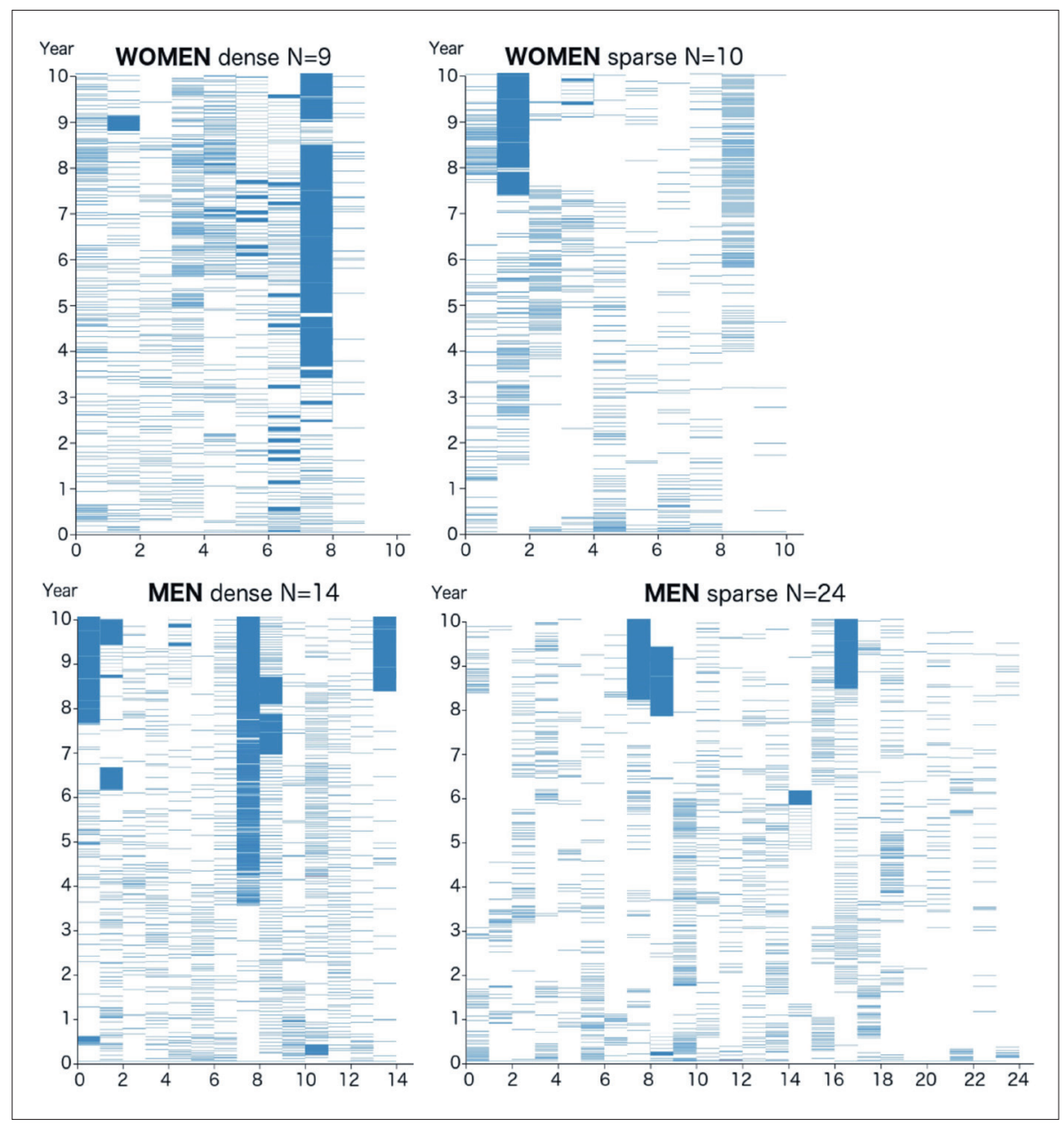

Fig. 6: Two-spheres long-term interventional trajectories: women at the top $(n=19)$, men below $(n=38)$ Source: authors' elaboration

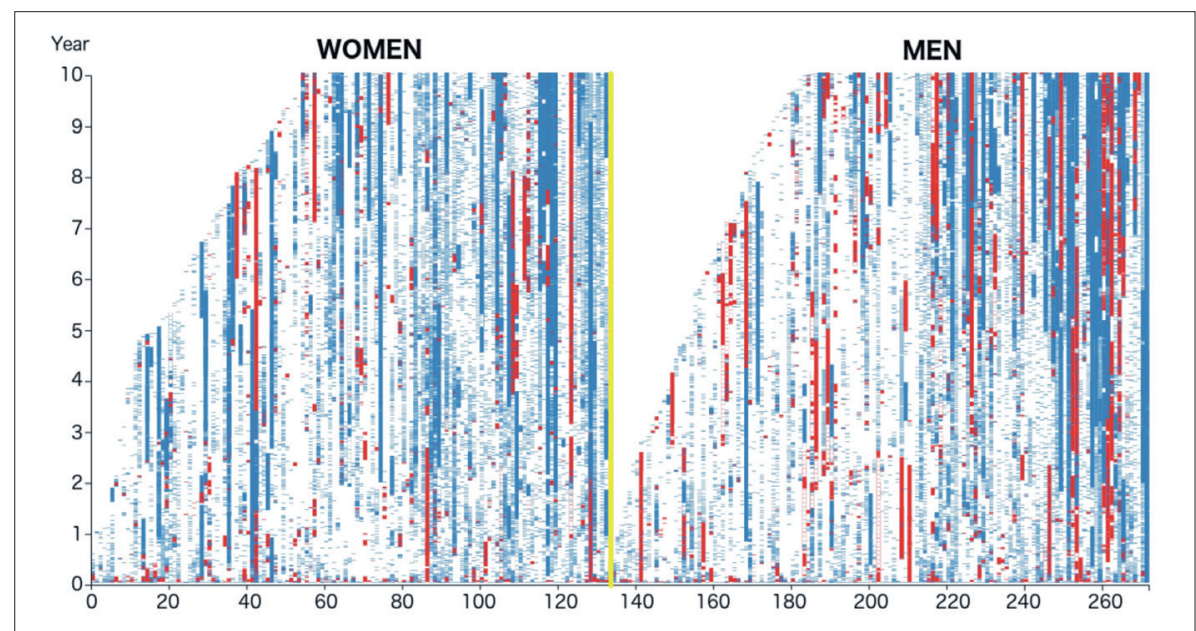

Fig. 7: Three-spheres trajectories: women to the left $(n=133)$, men to the right $(n=139)$ Source: authors' elaboration 


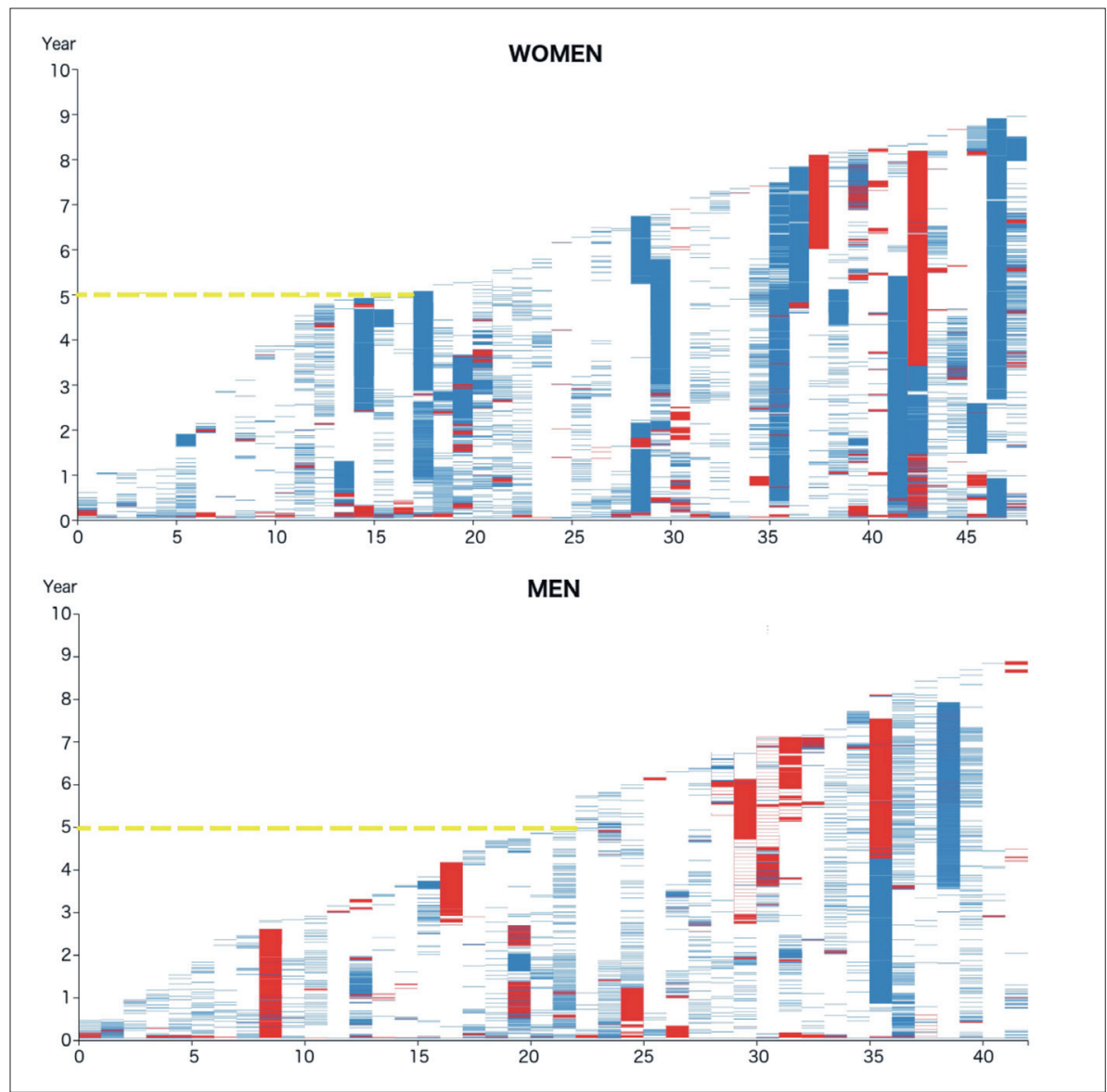

Fig. 8: Three-spheres stepwise trajectories: women above $(n=48)$, men below $(n=42)$. Source: authors' elaboration

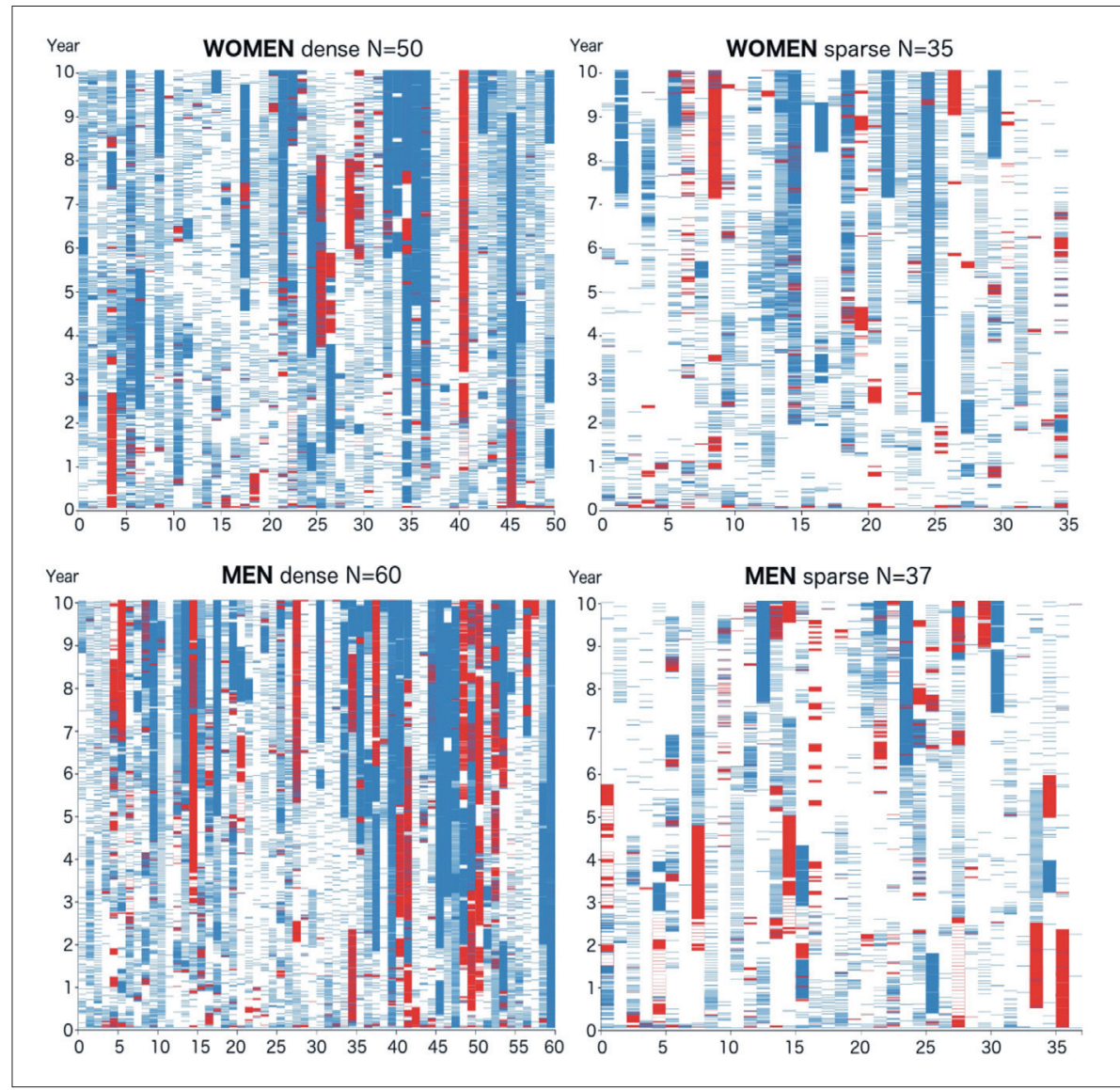

Fig. 9: Three-spheres long-term interventional trajectories: women at the top $(n=85)$, men below $(n=97)$. Dense trajectories to the left, sparse trajectories to the right. Source: authors' elaboration 


\begin{tabular}{|c|c|c|c|}
\hline $\begin{array}{l}\text { Women } \\
(\mathbf{N}=176)\end{array}$ & $\begin{array}{c}\text { Total } \\
\% \text { (number) }\end{array}$ & $\begin{array}{l}\text { Two-spheres } \\
\mathbf{N}=\mathbf{2 5} \%(\mathbf{4 3})\end{array}$ & $\begin{array}{l}\text { Three-spheres } \\
\mathbf{N}=\mathbf{7 5} \%\end{array}$ \\
\hline \multirow[t]{2}{*}{ Stepwise } & $40 \%(72)$ & $14 \%(24)$ & $27 \%(48)$ \\
\hline & $\mathrm{E}: 18 \%(32)$ & E: $8 \%(15)$ & $\mathrm{E}: 10 \%(17)$ \\
\hline \multirow[t]{3}{*}{ Long-term } & $60 \%(104)$ & $11 \%(19)$ & $48 \%(85)$ \\
\hline & $\mathrm{S}: 26 \%$ & S:6\% (10) & $\mathrm{S}: 20 \%(35)$ \\
\hline & D: $33 \%$ (59) & D:5\% ( 9$)$ & $\mathrm{D}: 28 \%(50)$ \\
\hline $\begin{array}{c}\text { Men } \\
(\mathrm{N}=\mathbf{2 0 8})\end{array}$ & $\begin{array}{c}\text { Total } \\
\% \text { (number) }\end{array}$ & $\begin{array}{l}\text { Two-spheres } \\
\mathbf{N}=33 \%(69)\end{array}$ & $\begin{array}{c}\text { Three-spheres } \\
\mathbf{N}=67 \% 139\end{array}$ \\
\hline \multirow[t]{2}{*}{ Stepwise } & $35 \%(73)$ & $15 \%(31)$ & $20 \%(42)$ \\
\hline & E: $16 \%(34)$ & $\mathrm{E}: 6 \%$ (12) & E: $11 \%(22)$ \\
\hline \multirow[t]{3}{*}{ Long-term } & $65 \%(135)$ & $18 \%(38)$ & $47 \%$ (97) \\
\hline & S: $29 \%$ ( 61) & $\mathrm{S}: 11 \%(24)$ & S: $18 \%(37)$ \\
\hline & D: $36 \%$ ( 74$)$ & D: $7 \%(14)$ & D: $29 \%(60)$ \\
\hline
\end{tabular}

Tab. 3: Main and sub-categories, according to $\operatorname{sex}(E=$ Early leavers, $S=$ Sparse, $D=$ Dense) Source: authors' elaboration

\section{Discussion}

This article contributes new knowledge about men and women diagnosed with psychosis as subjects to interventions offered by society from the year of diagnosis and ten years later. People with severe mental illness faced a different landscape of interventions after the era of the large institutions, and still the knowledge of what types of interventions, when they occur and for how long, has been insufficient. In this article we explored when they experienced what interventions and identified periods without interventions. We used a timegeographic approach and studied the consequent trajectories of these women and men.

\subsection{Diversity of patterns}

First of all, the trajectories show a great diversity. As noted in the introduction, Ciompi (1980) and Harrison et al. (2001) stated that there is no given direction in the life-course after being diagnosed with schizophrenia but rather a "striking heterogeneity" (Harrison et al., 2001, p. 516). The overall result of our research confirms this conclusion: men and women who get the diagnoses of psychosis for the first time, can go on with their lives in many different directions, shaping a great variety of trajectories. While Ciompi (1980) used typologies to illustrate different courses, this study follows each of the 384 individuals on aggregate level during the whole 10-year period. This unique approach is grounded on the time-geographical prerequisite concerning the indivisible individual, and a time-geographic visualisation method is used that allows us to closely follow each indivisible individual, year after year without interruption, showing when $\mathrm{s} /$ he is subject to different types of interventions, as well as periods with no interventions.

In this discussion, we will highlight the existence of the no interventions sphere. This is based on the timegeographic concept of the indivisible individual, combined with the fact that previous studies focus on interventions, not recognising that, after the institutional care era, periods of no interventions may appear in most people's lives that might not be analysed as an abandonment of persons' need of help. Not being in the interventional sphere for more than a year was our main tool to analyse different patterns. The result was an aggregated pattern of all individuals, some who stepwise left the two spheres of interventions, and others who were in these two spheres during the whole follow-up period (long-term trajectories). These aggregate patterns pointed out differences between trajectories with long and/ or recurrent periods without interventions (sparse patterns) and trajectories with short or no intermissions between interventions (dense patterns).

\subsection{Recovery}

The discovery that interventions could cease to appear at any time in a trajectory, with no more interventions during the rest of the 10-year period, can be related to the research field of recovery. Recovery in mental health has different definitions (Davidson and Roe, 2007; Slade et al., 2012; Topor et al., 2018). Our data does not give us the possibility to relate them to "personal recovery", defined as the persons' experience of their situation. Our data can however be related to the concept of clinical or institutional recovery, based on the person's use of mental health services.

The lengths of the follow-up periods that states when a person is recovered has been debated. Although cut-off periods of two years are not uncommon, several studies argue that a five-year period gives a more stable outcome (Laudet, 2007; Topor et al., 2018; Torgalsboen and Rund, 1998). Our data allow us to choose a five-year time span (as used for medical conditions such as cancer). From such a point of departure, $18 \%$ of the women and $16 \%$ of the men in this study can be regarded as recovered from psychosis. In our study, we consider all types of interventions, and the result shows that being subject to institutional care does not necessarily seem to have a substantial impact on the possibility to leave the interventional sphere at early stage.

Since the follow-up period is as long as 10 years, and the individuals are regarded as indivisible, thereby including periods with no interventions, we might add a new dimension to recovery from psychosis. The sparse patterns reveal that there are no intervention periods "in-between" interventions. Compared to follow-up studies that only pinpoint specific moments (see for example, Harrison et al., 2001; Wiersma et al., 1998), this method brings us a more thorough knowledge about the total situation during a coherent period of life. Even if a person is subject to interventions at the end as well as at the beginning of the longer follow-up period, there could be years without interventions in between. In this 
study these intermissions could last up to several years and/ or recurrent at several times during the 10 -year period. This indicates that a person can get by during substantial periods of time with no interventions, and just occasionally need attention from service providers.

\subsection{Spheres and constraints}

The three spheres in which people with SMI live their lives, lingering from one sphere to another, are characterised by similar constraints, but with different outcomes. The results from this study give insights about how people who are subject to interventions from the different spheres in the fragmented interventional landscape, meet the timegeographic constraints. We will compare this situation with the old institutionalised care system. There are both different and similar effects of the constraints for an individual's life, in the two different eras of organising SMIinterventions.

As mentioned in the introduction, the former institutions were not only secluded from the rest of society, they also controlled major parts of a person's life (Castel, 1988; Foucault, 1961/1989; Goffman, 1961). Reconnecting to the time-geographic constraints, most aspects of life were performed in one place under authority constraints controlled by one authority, in contrast to life in the rest of society where a manifold of organisations impose various authority constraints. Coupling constraints were reflected in different ways: the patients in former institutions were often far away from home, family and friends and had very limited possibilities to maintain social relationships (Kjellman, 2003). Thus, social interaction mainly involved two social categories: other patients, and staff, strongly coupled to each other. In terms of capacity constraints, expectations that the mental hospitals would improve the psychiatric status and decrease the capacity constraints of the individuals caused by SMI, were obscured by research showing that the effects of hospitalisation enhanced capacity constraints rather than reversed them (Barton, 1959; Wing and Brown, 1970).

A relevant question is whether the sphere of institutional interventions might be regarded as a prolongation of the former institutions. While modern institutional care under surveillance is mostly on a short-term basis (Andersson et al., 2019), the constraints cannot be compared to former institutional care. Supported housing is more a long-term project and may reveal some contradictions on the matter. It may enhance the possibilities of normalised living conditions (as a place of your own) and enhanced access to control your daily life (indicating less authority constraints) and supporting staff may help to decrease capacity constraints (Andersson, 1997, 2016; Ruud et al., 2019). But internal rules (for example participation in activities, compulsory contact with social services/psychiatry, cooperation with staff) indicate the possibility of extensive authority restrictions. Staff will also have knowledge about many aspects of a person's everyday life, with the possibility to affect decisions and ways of living. Authority constraints can thereby still inflict heavily on a person's life and supported housing, originally based on the idea of normalisation, may in that sense possibly be seen as re-institutionalisation (Andersen et al., 2016; Topor et al., 2015). The coupling constraints can also recall the former institutions, as social life can still mainly consist of two social categories - professionals and co-habitants (Andersson, 1997, 1998), although not necessarily constrained by housing authorities but the person's capacity in terms of resources, for example, poor economy, limiting the possibilities to interact in social life (Topor et al., 2014; Ware and Goldfinger, 1997; Wilton, 2003).

Most people (2/3) in this study have experience of institutions, but for most of them just for shorter periods. This means that they mainly live in a regular home. The common denominator for the regular home is that there are no constraints associated with the home relating to the resident's psychiatric problems. They have the same rights and obligations as other citizens.

The community-based sphere, as well as the no interventional sphere, involves an ordinary home as a base for living, including the surrounding society. The sphere of community-based interventions, then, is a combination of regular living conditions (such as a home) and an intervening society. This weakens the authority constraints (compared to institutional living) and may decrease the influence of capacity constraints on the individual. Community-based interventions involve both psychiatry and social services, and interventions may take place at an office/ clinic as well as in a person's private home, with the intentions to enhance a person's capacities and to eventually manage a life on their own. At the same time, as the interventions might decrease capacity constraints, authority constraints may increase by the presence of officials obtaining increased influence and insights in the private life and home (Andersson, 2009; Chow and Priebe, 2013; Fakhoury and Pribe, 2007; Foucault, 1975; Topor, et al., 2015).

In the sphere of no interventions, people live under similar circumstances and are influenced by similar constraints as other people. Periods of no intervention in the trajectory of a person with SMI can be regarded as personal or private, where authorities connected to the psychiatric problems are not involved. Home is in that sense a protected area. Still, a combination of authority and coupling constraints exist that affect the lives of persons with severe psychiatric problems, who are depending on the welfare system: poor economy (Read, 2010). This influences an individual's possibilities to master social life in the wider society and may strongly affect her/his opportunities to utilise the weaker coupling constraints a life outside institutions could offer, partly due to economy.

As stated earlier, the different types of constraints are mutually related and influence peoples' opportunities to interact and carry out activities (Westermark, 2003). The individual's room for manoeuvre is in this way regarded as limited (Lenntorp, 1976), regardless of where and how a person lives. Persons with severe psychiatric problems may face specific constraints depending on the spheres in which their lives take place. Authority constraints, such as surveillance, may restrict life in supported housing, but can also influence life in ordinary accommodations with the presence of community-based care and support. Authority constraints in terms of the rules of the welfare system may have effects regardless of sphere, as the poor economy affects the possibility to interact in social life and enhance coupling restrictions.

\section{Conclusions}

In this article we have stated that the 10 -year outcome for persons diagnosed with psychosis for the first time can be substantially diverse, and that it always includes periods of no intervention. This knowledge could have implications on attitudes and expectations among professionals in this 
field, in that a diagnosis of psychosis does not necessarily mean life-long interventions. Keeping the perspective of the indivisible individual is the key to understanding how life turns out in the long run for persons with severe psychiatric problems: not only investigating periods of interventions, but with equal interest, examining the sequences without interventions. Only with fully exposed trajectories during the whole follow-up period, using this visualisation method, can this evaluation be carried out.

\section{Acknowledgment}

This article is a part of a larger research project: "Persons with severe mental illness - living conditions, interventions and paths. A ten-year follow-up", financed by the Swedish Research Council for Health, Working life and Welfare, Grant Nr: 2014-0117.

\section{References:}

ABDIN, E., CHONG, S. A., VAINGANKAR, J. A., PEH, C. X., POON, L. Y., RAO, S., ... SUBRAMANIAM, M. (2017): Trajectories of positive, negative and general psychopathology symptoms in first episode psychosis and thevir relationship with functioning over a 2-year followup period. PloS one, 12(11): e0187141.

ANDERSEN, A. J. W., LARSEN, I. B., TOPOR, A. (2016): Caring through discipline? Analyzing house rules in community mental health services in Norway. Scandinavian Psychologist, 3: e1.

ANDERSSON, G. (1997): En gruppbostad blir till dokumentation av psykiatrireformen, delrapport I. Hägersten och Liljeholmens stadsdelsförvaltningar, Stockholms stad.

ANDERSSON, G. (1998): En gruppbostad - första året. Dokumentation av psykiatrire-formen, delrapport II. Hägersten och Liljeholmens stadsdelsförvaltningar, Stockholms stad.

ANDERSSON, G. (2009): Vardagsliv och boendestöd - en studie om människor med psykiska funktionshinder. Avhandling. Stockhom, Stockholms Universitet, Institutionen för socialt arbete.

ANDERSSON, G. (2016): What makes supportive relationships supportive? The social climate in supported housing for people with psychiatric disabilities. Social work in mental health, 14(5): 509-529.

ANDERSSON, G., GUSTAFSSON, H., BRINGLÖV, A. (2015): Boendestöd - Stockholm Södertörn Gotland. Delrapport: Intervjustudie. FoU Södertörns skriftserie nr 133/15. FoU Södertörn.

ANDERSSON, G., ELLEGÅRD, K., BÜLOW, P., DENHOV, A., VROTSOU, K., STEFANSSON, C. G., TOPOR, A. (2019): A longitudinal study of men and women diagnosed with psychosis: trajectories revealing interventions in a timegeographic framework. GeoJournal, 2019: 1-18.

ÅQVIST, A. (1992): Tidsgeografi i samspel med samhällsteori. Dissertation. Lund, Lunds Universitet, Geografiska Institutionen.

ARVIDSSON, H. (2008): The development of needs in a group of severe mentally ill - A 10-year follow-up study after the 1995 Swedish mental health care reform. Social Psychiatry and Psychiatric Epidemiology, 43(705): 705-713.
BARDER, H. E., SUNDET, K., RUND, B., EVENSEN, J., HAAHR, U., HEGELSTAD, W., ... MELLE, I. (2013): Ten year neurocognitive trajectories in first-episode psychosis. Frontiers in human neuroscience, 7: 643.

BARDER, H. E., SUNDET, K., RUND, B. R., EVENSEN, J., HAAHR, U., TEN VELDEN HEGELSTAD, W., ... MELLE, I. (2015): 10 year course of IQ in first-episode psychosis: Relationship between duration of psychosis and long-term intellectual trajectories. Psychiatry Research, 225(3), 515-521.

BARTON, R. (1959): Institutional neurosis. Bristol, Wright.

BECKER, T., VÁZQUEZ-BARQUERO, J. L. (2001): The European perspective of psychiatric reform. Acta Psychiatrica Scandinavica, 104 (410): 8-14.

BORG, M., SELLS, D., TOPOR, A., MEZZINA, R., MARIN, I., DAVIDSON, L. (2005): What Makes a House a Home: The Role of Material Resources in Recovery from Severe Mental Illness. American Journal of Psychiatric Rehabilitation, 8(3): 243-256.

BÜLOW, P. (2004): Efter mentalsjukhuset. En studie i spåren av avinstitutionaliseringen av den psykiatriska vården. Linköping dissertations on health and society, No. 5, Linköpings Universitet.

CASTEL, R. (1988): Regulation of madness. The origins of incarceration in France. Berkeley, University of California Press.

CHOW, W. S., PRIEBE, S. (2013): Understanding psychiatric institutionalization: a conceptual review. BMC Psychiatry, 13(1): 169.

CIOMPI, L. (1980): The natural history of schizophrenia in the long term. The British Journal of Psychiatry, 136(5): 413-420.

DAVIDSON, L., ROE, D. (2007): Recovery from versus recovery in serious mental illness: One strategy for lessening confusion plaguing recovery, Journal of mental health, 16(4): 459-470.

DAVIDSON, L., RAAKFELDT J., STRAUSS, J. (2010): The roots of the recovery movement in psychiatry. Lessons learned. Chichester, Wiley-Blackwell.

DEVERTEUIL, G., HINDS, A., LIX, L., WALKER, J., ROBINSON, R., ROOS, L. L. (2007): Mental health and the city: Intra-urban mobility among individuals with schizophrenia. Health \& Place, 13(2): 310-323.

DEVYLDER, J. E., MUCHOMBA， F. M., GILL， K. E., BEN-DAVID, S., WALDER, D. J., MALASPINA, D., CORCORAN, C. M. (2014): Symptom trajectories and psychosis onset in a clinical high-risk cohort: The relevance of subthreshold thought disorder. Schizophrenia Research, 159(2-3): 278-283.

ELLEGÅRD, K. (1983): Människa - produktion: tidsbilder av ett produktionssystem. Dissertation. Gothenbur, Gothenburg University.

ELLEGÅRD, K. (1998): Under ytan - ingångar till det kulturgeografiska äventyret. In: Gren, M. \& Hallin, P. O. [eds.]: Svensk kulturgeografi inför 2000-talet. Lund, Studentlitteratur.

ELLEGÅRD, K. (2001): Att hitta system i den välkända vardagen. En tankeram för studier av vardagens aktivitetsmönster och projekt. In: Ellegård, K. 
\& Wihlborg, E. (2001): Fånga vardagen. Ett tvärvetenskapligt perspektiv. Lund, Studentlitteratur.

ELLEGÅRD, K., VROTSOU, K. (2006): Capturing patterns of everyday life - presentation of the visualization method VISUAL-TimePAcTS. In IATUR - XXVIII Annual Conference, Copenhagen, Denmark, August 16-18.

ELLEGÅRD, K. (2019): Thinking Time Geography. Concepts, Methods and Applications. New York, Routledge.

FAKHOURY, W., PRIEBE, S. (2007): Deinstitutionalization and reinstitutionalization: major changes in the provision of mental healthcare. Psychiatry, 6(8): 313-316.

FOUCAULT, M. (1961/1989): Madness and civilization. A story of insanity in the age of reason. New York \& London, Routledge.

FOUCAULT, M. (1975): Surveiller et punir. Naissance de la prison. Paris, Gallimard. (Svensk övers. 1987) Övervakning och straff. Fängelsets födelse. Lund: Arkiv moderna klassiker.

GEORGACA, E., ZISSI, A. (2019): Socially differentiated life trajectories of individuals with experience of psychosis: A biographical study. Mental health \& prevention, 14: 100153 .

GOFFMAN, E. (1961): Asylums - Essays on the social situation of mental patients and other inmates. New York, Doubleday \& Co.

GONZÁLEZ-BLANCH， C., GLEESON, J.F., KOVAL， P., COTTON, S. M., MCGORRY, P. D., ALVAREZ-JIMENEZ, M. (2015): Social functioning trajectories of young first-episode psychosis patients with and without cannabis misuse: A 30-month follow-up study. PLoS One, 10(4): e0122404.

GREEN, C. A., PERRIN, N. A., LEO, M. C., JANOFF, S. L., YARBOROUGH， B. J. H., PAULSON， R. I. (2013): Recovery from Serious Mental Illness: Trajectories, Characteristics, and the Role of Mental Health Care. Psychiatric Services, 64(12): 1203-1210.

HALL, M. H., HOLTON, K. M., ÖNGÜR, D., MONTROSE, D., KESHAVAN, M. S. (2019): Longitudinal trajectory of early functional recovery in patients with first episode psychosis. Schizophrenia research, 209: 234-244.

HARRISON, G., HOPPER, K. I. M., CRAIG, T., LASKA, E., SIEGEL, C., WANDERLING, J. O. E., ... HOLMBERG, S. K. (2001): Recovery from psychotic illness: a 15and 25-year international follow-up study. The British journal of psychiatry, 178(6): 506-517.

HEGELSTAD， W. T. V., LARSEN, T. K., AUESTAD, B., EVENSEN, J., HAAHR, U., JOA, I., ... ROSSBERG, J. I. (2012): Long-term follow-up of the TIPS early detection in psychosis study: effects on 10-year outcome. American Journal of Psychiatry, 169(4): 374-380.

HÄGERSTRAND, T. (1970): What about people in regional science? Papers of the Regional Science Association, 24(1): 7-24.

HÄGERSTRAND, T. (1972). Om en konsistent individorienterad samhällsbeskrivning för framtidsstudiebruk. Ds Ju 1972:25. Specialarbete till Statens Offentliga Utredningar (SOU) 1972:59, Att välja framtid.

HÄGERSTRAND, T. (1973): The domain of human geography. In: Chorley, R. J. [ed.]: Directions in Geography. London, Methuen \& Co.
HÄGERSTRAND, T. (1974): Tidsgeografisk beskrivning syfte och postulat. Svensk Geografisk Årsbok Vol. 50.

HÄGERSTRAND, T. (1985): Time-geography: focus on the corporeality of man, society and environment. Reprinted from The Science and Praxis of Complexity. New York, United Nations University.

KJELLMAN, C. (2003): Studier av marginaliserade människors förändrade vardagsliv Dissertation. Lund, Lund University, Department of Human Geography.

LARSEN, B., TOPOR, A. (2017): A place for the heart: A journey in the post-asylum landscape. Metaphors and materiality. Health \& Place, 45: 145-151.

LAUDET, B. L. (2007): What does recovery mean to you? Lessons from the recovery experience for research and practice. Journal of Substance Abuse Treatment, 33(3): 243-256

LENNTORP, B. (1976): Paths in Space-Time Environments. A Time-geographic Study of Movement Possibilities of Individuals. Dissertation. Meddelanden från Lunds Universitets Geografiska Institution 1976. Avhandlingar LXXVII

LEVINE， S. Z., RABINOWITZ，J. (2010): Trajectories and Antecendents of Treatment Response Over Time in Early-Episode Psychosis. Schizophrenia Bulletin, 36(3): 624-632.

LINDQVIST, R., MARKSTRÖM, U., ROSENBERG, D. (2010): Psykiska funktionshinder i samhället. Malmö, Gleerups.

MARKLUND, U. (2005): Från mentalsjukhus till samhälle. In: Brunt, D., Hansson, L. [eds.]: Att leva med psykiska funktionshinder: livssituation och effektiva vård- och stödinsatser. Lund, Studentlitteratur

MILEV, P., HO, B. C., ARNDT, S., ANDREASEN, N. C. (2005): Predictive Values of Neurocognition and Negative Symptoms of Functional Outcome in Schizophrenia: A Longitudinal First-Episode Study With 7-Year FollowUp. American Journal of Psychiatry, 162(3): 495-506.

OOTS, S. T., POLS, A. J., TONKENS, E. H., WILLEMS, D. L. (2013): Where is the citizen? Comparing civic spaces in long-term mental healthcare. Health \& Place, 22: 11-18.

PELAYO-TERAN, J. M., DIAZ, F. J., PEREZ-IGLESIAS, R., SUAREZ-PINILLA, P., TABARES-SEISDEDOS, R., DE LEON, J., CRESPO-FACORRO, B. (2014): Trajectories of symptom dimensions in short-term response to antipsychotic treatment in patients with a first episode of non-affective psychosis. Psychological medicine, 44(1): 37-50.

PRIEBE, S., BADESCONYI, A., FIORITTI, A., HANSSON, L., KILIAN, R., TORRES-GONZALES, F., WIERSMA, D. (2005): Reinstitutionalisation in mental health care: comparisons of data on service provision from six European countries. British Medical Journal, 330(7483): 123-126.

PRIEBE, S., FROTTIER, P., GADDINI, A., KILIAN, R., LAUBER, C., MARTÍNEZ-LEAL, R., ... WRIGHT, D. (2008): Mental health care institutions in nine European countries, 2002 to 2006. Psychiatric services, 59(5): 570-573.

READ, J. (2010): Can Poverty Drive You Mad? 'Schizophrenia', Socio-Economic Status and the Case for Primary Prevention. New Zealand Journal of Psychology, 39(2): $7-19$ 
RUUD LINDVIG, G., LARSEN I. B., TOPOR, A., BØE, T. D. (2019): 'It's not just a lot of words'. A qualitative exploration of residents' descriptions of helpful relationships in supportive housing. European Journal of Social Work, 2019: 1-13.

SANCHEZ-TORRES, A. M., MORENO-IZCO, L., LORENTEOMENACA, R., CABRERA, B., LOBO, A., GONZALEZPINTO, A. M., ... BUTJOSA, A. (2018): Individual trajectories of cognitive performance in first episode psychosis: a 2-year follow-up study. European archives of psychiatry and clinical neuroscience, 268(7): 699-711.

SBU, Statens Beredning för medicinsk Utvärdering, (2012): Schizofreni. Läkemedelsbehandling, patientens delaktighet och vårdens organisation - En systematisk litteraturöversikt. Stockholm, SBU.

SCHÖN, U. K. (2010): Recovery from severe mental illness, a gender perspective. Scandinavian Journal of Caring Science, 24(3): 557-564.

SLADE, M., LEAMY, M., BACON, F., JANOSIK, M., LE BOUTILLIER, C. WILLIAMS, J., BIRD, V. (2012): International differences in understanding recovery; systematic review, Epidemiology and Psychiatric Sciences, 21(4): 353-64.

TOPOR, A., MATTSSON, M., DENHOV, A., BÜLOW, P., HOLMQVIST, S., DAVIDSON, L. (2011): The Stockholm Follow-up Study of Users Diagnosed with Psychosis (SUPP): Methodology, patient cohort and services. Psychosis, 4(3): 246-257.

TOPOR, A., ANDERSSON, G., DENHOV, A., HOLMQVIST, S., STEFANSSON, C. G., BÜLOW, P. (2014): Psychosis and poverty: Coping with poverty and severe mental illness in everyday life. Psychosis, 6(2): 117-127.

TOPOR, A., ANDERSSON, G., BÜLOW, P., STEFANSSON C. G., DENHOV A. (2015): After the Asylum? The New Institutional Landscape. Community Mental Health Journal, 52(6): 731-737.

TOPOR, A., STEFANSSON, C. G., DENHOV, A., BÜLOW, P., ANDERSSON, G. (2018): Institutional recovery: a 10-year follow-up of persons after their first psychosis diagnosis. A critical reflexive approach. Psychosis 10(4): 263-274.

TOPOR, A., STEFANSSON, C. G., DENHOV, A., BÜLOW, P., ANDERSSON, G. (2019): Recovery and economy; salary and allowances: a 10-year follow-up of income for persons diagnosed with first-time psychosis. Social Psychiatry and Psychiatric Epidemiology, 54(8): 919-926.
TOWNLEY, G., KLOOS, B., WRIGHT, P.A. (2009): Understanding and experience of place: Expanding methods to conceptualize and measure community integration of persons with serious mental illness. Health \& Place, 15(2): 520-531.

TORGALSBOEN, A. K., RUND, B. B. (1998): "Full recovery" in schizophrenia in the long term. A ten-year followup of eight former schizophrenic patients. Psychiatry, 61(1): 20-34.

VROTSOU, K. (2010): Everyday mining: Exploring sequences in event-based data. Linköping studies in science and technology. Dissertations Nr. 1331, Linköping University, Sweden.

VROTSOU, K., ANDERSSON, G., ELLEGÅRD, K., STEFANSSON, C. G., TOPOR, A., DENHOV, A., BÜLOW, P. (2017): A time-geographic approach for visualizing the paths of intervention for persons with severe mental illness. Geografiska Annaler: Series B, Human Geography, 99(4): 341-359.

WARE, N. C., GOLDFINGER, S. M. (1997): Poverty and rehabilitation in severe psychiatric disorders. Psychiatric Rehabilitation Journal, 21(1): 3-7.

WESTERMARK, Å. (2003): Informal livelihoods: Women's biographies and reflections about everyday life. A timegeographic analysis in urban Columbia. Dissertation. Handelshögskolan, Göteborgs universitet.

WIERSMA, D., NIENHUIS, F. J., SLOOFF, C. J., GIEL, R. (1998): Natural Course of Schizophrenia Disorders: A 15-year Follow-up of a Dutch Incidence Cohort. Schizophrenia Bulletin, 24(1): 75-85.

WILTON, R. D. (2003): Poverty and mental health: A qualitative study of residential care facility tenants. Community Mental Health Journal, 39(2): 139-156.

WING, J. K., BROWN G.W. (1970): Institutionalism and schizophrenia - A comparative study of three mental hospitals 1960-1968. Cambridge, Cambridge University Press.

WOLCH, J., PHILO, C. (2000): From distributions of deviance to definitions of difference: past and future mental health geographies. Health \& Place, 6(3): 135-157.

\section{Please cite this article as:}

ANDERSSON, G., VROTSOU, K., DENHOV, A., TOPOR, A., BÜLOW, P., ELLEGÅRD, K. (2020): A diversity of patterns: 10-year trajectories of men and women diagnosed with psychosis for the first time. A time-geographic approach. Moravian Geographical Reports, 28(4): 283-298. Doi: https://doi.org/10.2478/mgr-2020-0021 